\title{
Food Ordering System in College Canteens Designed Using Python
}

\author{
Vivek Prasad, Nikhun Jena, Ajinkya Panday, Nisha Patil \\ SOCSE, Sandip University, Nashik, Maharashtra, India
}

\begin{abstract}
Article Info

Volume 7, Issue 3

Page Number: 505-508

Publication Issue :

May-June-2021

\section{Article History}

Accepted : 01 June 2021

Published : 07 June 2021

This document provides an observational solution to the daily observed problem that are faced by multiple students all over India and so did we face in our college. Usually, the average time period for Breakfast and Lunch break are 15 and 40 mins respectively. Due to huge campus infrastructure the department has placed multiple canteens for better reach for students, but increasing number of students in department like Engineering, Medical Architecture, Law, Fashion Designing has hampered the Time Management of Canteens and students meaning the time allotted to students isn't enough to carry along for the Day and in reciprocating in causing multiple health issues in growing students, In order to bring rest to this un-managed problem we decided to create an app that would solve this problem at the user end as well at the management end saving time and manage scheduling food orders with limited man resource in respective time slot allotted to the students.
\end{abstract}

Keywords : Observational Analysis, Food ordering, Time and Resource Management.

\section{INTRODUCTION}

Food ordering in colleges has been the most difficult times a student has had in his or her college life.

Allotted time to reach a canteen, waiting for your turn, ordering your meal and then having it is just ideally allotted by the colleges but very impractical with the number of students and no. of canteens in the college.

This was the observational problem that we recorded and found a practical solution to apply in our environment first.
On an average there are about 4000 Engineering colleges and 6000 rest of them. At present, the higher education sector in India consists of 3.74 crore students across 993 universities, 39,931 colleges, and 10,725 stand-alone institutions, according to the AISHE-2019.

The importance of time and management in a student's life is crucial and to compromise it for food was not appropriate so we made an app based on comprehensive study and observation using python. This particular research paper will give you the brief idea of how the application is designed and what are the parts that are involved in making such an application and the practical scope in the everyday 
life. A huge amount of post research work involving number all-round the nation of students' colleges and canteens were gathered and analysed and accordingly knowing the scope of this solution solving the problem we made this application. The prototype of this made accordingly knowing our parameter.

The architectural model of the application works on 8 main parts of execution, which are: -

1. The Main Strata

2. The Food Ordering bit

3. The File Reader bit

4. The File Sorter bit

5. The Drink Ordering bit

6. Overhead Services bit

7. The Final Order heck bit.

8. The Checkout bit

The distribution of this execution bits is made so that the coder and the architectural lead must need to know their workflow and make sure that the levels are completely running.

The organization of this document is as follows. In Section 2 (Literature Review), I'll give detail of any modifications to equipment or equipment constructed specifically for the study and, if pertinent, provide illustrations of the modifications. In Section 3 (Approach and Analysis), present your research findings and your analysis of those findings. Discussed in Section 4(Conclusion) followed by Section 5 (Acknowledgement and References)

\section{LITERATURE REVIEW}

1. The primary objective of this research paper is to make sure that the Audience reading it and researching about the students in Indian Education System must know the numbers, facts and statistics. This will give them visual representation of the current scenario dated January 2021.

2. The Research paper is the implication of a perfect resolution to the mass problem of the country. Using various data analytic software like Tableau we get to know the scope of utilization of the application we created by users.

3. This particular application that monitors canteens in the college campuses enables the end clients to register on the online, read and select the food from e-menu card and order food online by simply choosing the food that the client needs to have to utilize the android application.

4. By utilizing this application work by the man resources in the canteens would be reduced and we can likewise say that the work is invalidated. The advantage of this is if there is the rush in the Canteen at that point there will be chances that the waiters will be unavailable and the clients can directly order the food to the chef online by utilizing this application.

5. The system is the mix of Android and Web Application where the main strata is designed and built around python.

6. The architecture of the entire use interface is so basic and easily developed creating minimal man errors and avoiding mishaps.

7. It allows user to see the desire canteen of their choice and flexibility considering their location in the campus, then see the menu available along with the place, choose and select the quantity of the dish required, Verify the menu before placing the order and also check out through the option of paying through various online payment methods.

8. The working of the bits in the architecture Is so smooth and efficiently built allowing canteen employees and resources to quickly go through the orders as they are placed by the user directly and produced the necessary order without the delay and confusion. 


\section{III.APPROACH AND ANALYSIS.}

This part of the paper will allow the readers to understand the core of the entire project. The project has involved deep research using various data analysis tools. After verifying the data, we move our step to build the body of the application and then run a test to make sure the working is smooth and efficient without any traffic load over the application.

The following are the deep workings and the details of the project.

\section{A. Architectural Approach}

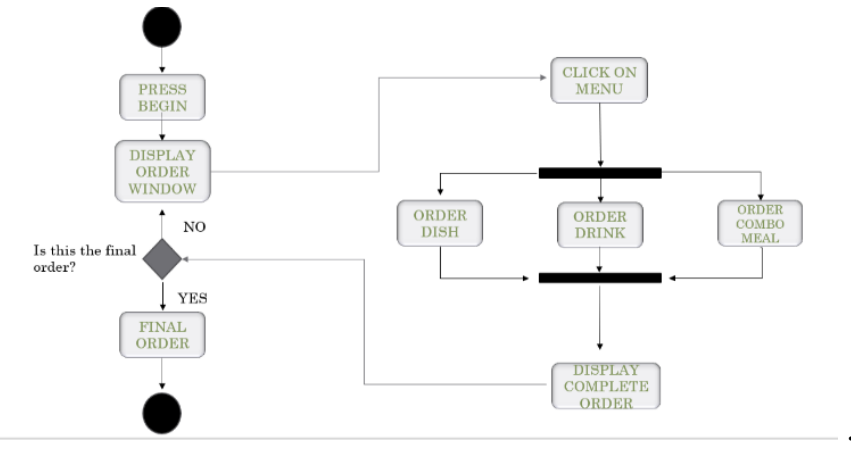

The Architecture is supported with strong graphical user interface so that it makes the user interaction over the application very Suttle and friendly.

\section{B. The working of the bits.}

To make sure that the code and architecture of the algorithm works efficiently the workflow of the application is divided into few parts or bits which when implemented correctly will lead to the working of the entire project successfully.

\section{The Main body / Strata}

The Main strata involves compounding of other bits. In order to make sure that each bit works well they are defined in the main strata and with help of algorithm made to run simultaneously according the position of execution.

\section{The Food Ordering Bit.}

In this particular half the food menu is been allotted so that the user gets a variety of choices in various categories of dishes available with the respective canteens. The other half of the bit is been worked to make sure it integrates with the Main strata.

\section{The Food Reading Bit}

The reading bit allows the algorithm to make sure it read every line in the food ordering menu. This is done to ensure that the data received and the data sent is properly monitored and there is no line of implementation been missed.

\section{The Food Sorter Bit}

This particular bit makes sure that the food items are properly sorted with respective categorical choice and that they are sorted either alphabetically or on preference of most ordered dish or the bestselling dish.

\section{The Drinking Order Bit}

This bit has algorithm attaching various line of drinks available on the platform and reconciling them to the main strata ensuring that the bit runs without any compilation errors.

\section{Overhead Services Bit}

This part of the architecture involves adding overhead commodities that are predefined by the canteens that are registered in the application. These are cost implementing services that are provided to the users or students in order to make the delivery service of the application efficient and student easy.

\section{The Final Order Bit Check}

This the final page that is been put forth as the last step of the process of ordering food in the application. This make sure that the report of your order is been made and reviewed by the user or the student and also the link over to this page is made to the payment 
gateway. A part of the algorithm also allows the final report after the payment to the home page allowing them to track their order and preparation time.

\section{The Checkout Bit}

This page is link followed after the final report of the order.

The Checkout comes with various modes of the gateway like COD (Cash On Delivery), UPI, Net banking, Credit/ Debit Cards. .

\section{CONCLUSION}

In today's competitive world for students their time is the most important asset they can productively utilize but in order to do that they compromise on their health unknowingly.

A Realtime problem of students facing delayed food Service in their colleges bring them to attend their rest of their schedule without proper recess or lunch break.

Growing number of students in each field of education in their respective college is increasing with rate of minimal 5\% every year. This is leading to nothing but improper canteen management and unbalanced time allotted to the students to have their meals.

In order to divert this topic, this particular application is made and ensure that works efficiently avoiding all the causalities.

It helps restraining factors like Time Management, Student to Canteen Order Ratio, Canteen Resource Management and Efficient Workload System.

\section{ACKNOWLEDGMENT}

It is with a very warm sense of gratitude and privilege that we would like to acknowledge the efforts of the people who helped us with the ideation, creation and subsequent execution of this Final Year Project. Firstly, we would like to thank our Chief
Project Mentor, Professor Nisha Patil, for pushing us beyond our limits in all the right directions with regards to our project. Her omnipresent guidance and support have been invaluable to the delivery of our project. We would also like to thank our esteemed Dean, for handing us this opportunity to enhance and hone our skills in a practical application of our curriculum. We would also like to mention the constant support we have received from our classmates, if and when it was required. This project wouldn't have come such a long way without it. Lastly, our gratitude to the institution itself, for helping us develop our skills and build a foundation upon which this project could be laid in our final year as students.

\section{REFERENCES}

[1]. https://www.getmyuni.com/articles/totalengineering-colleges-in-india

[2]. https://en.wikipedia.org/wiki/Higher_education_in_ India

[3]. https://theprint.in/india/education/study-showshow-indias-higher-education-enrollment-canjump-to-65-from-27/441582/

[4]. https://www.google.com/url?sa=t\&source=web\&rct= j\&url=https://www.communitycollegereview.com/a verage-college-size-stats/nationaldata\&ved=2ahUKEwietbqH7_zwAhVXzjgGHeCxA hoQFjACegQIExAF\&usg=AOvVaw3vXFbkIirtK_0ss FRDo2ah

[5]. https://www.cdc.gov/healthyschools/nutrition/scho ol_lunch.htm

\section{Cite this article as :}

Vivek Prasad, Nikhun Jena, Ajinkya Panday, Nisha Patil, "Food Ordering System in College Canteens Designed Using Python", International Journal of Scientific Research in Computer Science, Engineering and Information Technology (IJSRCSEIT), ISSN : 2456-3307, Volume 7 Issue 3, pp. 505-508, May-June 2021. Available at doi $\quad:$ https://doi.org/10.32628/CSEIT2173112

Journal URL : https://ijsrcseit.com/CSEIT2173112 